\title{
A preliminary study on the possible effects of the acute zinc administration on the anxiety- like behaviour
}

\author{
Constantin Truş, Roxana Rosmary Enciu
}

\begin{abstract}
Constantin Truş - Associate Professor, Department of Morphological and Functional Sciences, Faculty of Medicine, Dunarea de Jos University, Galaţi, Romania

Roxana Rosmary Enciu - MD, "Sf. Apostol Andrei” General and Emergency Hospital Galaţi
\end{abstract}

\begin{abstract}
Zinc ions are trace elements in the human body with key regulatory role over numerous structural, transcriptional and enzymatic proteins essential for the correct function of the central nervous system. In the present work we were interested in determining the possible relevance of acute zinc administration on the anxiety-like behaviour. Our initial results described here show a promising relevance for zinc in anxiety-related context and advocate for further research, considering oxidative stress related mechanisms.
\end{abstract}

\section{KEYWORDS:}

Zinc, biotechnological, anxiety, oxidative stress.

\section{INTRODUCTION}

Zinc ions are some of the most abundant trace elements in the human body. Among many important functions, zinc ions regulate numerous structural, transcriptional and enzymatic proteins that play important roles in the correct function of the central nervous system $(1,2,3)$. Therefore, zinc is considered to be essential for brain development function (3).

Up to date there is not a clear consensus regarding the effect of a zinc deficient diet on the brain. On one hand, zinc homeostasis in the brain is known to be strictly regulated by the brain barrier system, and, therefore, is not easily affected by a zinc deficient diet $(4,5)$. However, certain studies have demonstrated that some neuronal functions are impaired by a diet low in zinc (6).

For example, learning and memory are impaired before any decrease in zinc concentration can be observed in the brain of experimental animals fed a zinc-deficient diet. Specifically, one study showed that zinc concentration in the brain of rats did not decrease after a 4-week zinc deprivation, whereas a significant impairment in the learning behaviour of passive avoidance was 
r.\%\%

observed (7). Thus, the significance of zinc homeostasis in the brain neuronal function is still not fully understood.

Regarding the importance of zinc in a healthy diet and the possible negative outcomes of zinc deficient diet, approximately $50 \%$ of the world population does not get an optimal quantity of zinc, according to K. Brown et al. (8).

It has been demonstrated that zinc deficiency in children is a real nutritional and health problem in both developing and developed countries (10). This should raise serious concerns, especially when the evidence from animals experimental studies indicates that zinc deprivation during periods of rapid development critically impairs behaviour and brain function, in addition to brain development $(11,12)$.

One of the main behavioural symptoms of zinc deficiency is lethargy, characterized by reduced activity and responsiveness (13). Furthermore, zinc supplementation has been shown to improve neuropsychological behaviours in school-age children $(14,15)$.

However, the mechanisms underlying brain impairments in zinc deficiency are still unclear and further analysis on the relationship between neuropsychological behaviour and neuronal function in zincdeficient animal models are necessary to a better understanding.

The possible correlation between zinc level and anxiety, could be implied by that the highest levels of zinc in the central nervous system are found in areas known to be important in anxiety, including the cerebral cortical part of the brain, the hippocampus, most amygdaloid nuclei and the lateral septum (16).
In addition, although zinc deprivation does not seem to influence brain zinc homeostasis, however zinc deprivation leads to alteration in behaviour, learning, mental function and may cause epileptic convulsions (18).

Several studies have indicated that zinc is also involved in the pathophysiology of depression and in the mechanism of antidepressants (19, 20, 21 ,22). Animal models-based investigations have suggested that zinc produces similar effects to those of known antidepressants in various animal tests such as the forced swim test and the tail suspension test $(23,24,25)$.

Furthermore, there are clinical data showing that zinc supplementation may present benefits for patients who suffer from unipolar depression $(26,27)$.

In the present study, we have investigated the effect of acute administration of zinc in rats in the elevated plus maze test.

\section{MATERIALS AND METHODS}

Animals and drug treatment

The experiments were performed on male Wistar rats (220-280 g). The animals were kept under a natural day/night cycle at room temperature $\left(22-25^{\circ} \mathrm{C}\right)$, with free access to food and water. The design of our study had 5 experimental groups, consisting of 8 animals each: the control group and 4 groups of zinctreated rats which received increasing zinc hydroaspartate doses of $8.125 \mathrm{mg} / \mathrm{kg}, 16.25$ $\mathrm{mg} / \mathrm{kg}, \quad 32.5 \mathrm{mg} / \mathrm{kg}$ and $65 \mathrm{mg} / \mathrm{kg}$ respectively.

Experiments were conducted between 9:00 a.m. and 2:00 p.m. by an observer who was blinded to the treatment.

Zinc hydroaspartate dissolved in aqua pro injections or vehicle (control) was 
administered intraperitoneally in a volume of $2 \mathrm{ml} / \mathrm{kg}, 45 \mathrm{~min}$ before the test.

These doses were selected based on previous data from literature $(28,29)$.

Rats were treated in accordance with the guidelines of the animal bioethics of the Act on Animal Experimentation and Animal Health and Welfare from Romania and all procedures performed in studies involving animals were in compliance with Directive 2010/63/EU of the European Parliament and of the Council of 22 September 2010 on the protection of animals used for scientific purposes.

\section{Elevated plus maze test}

The testing procedure was based on a method described by Pellow and File (30). The apparatus, consisted of two open arms $(50 \times$ $10 \mathrm{~cm})$ and two closed arms $(50 \times 10 \mathrm{~cm}$ with 30-cm-high walls), arranged in a "+" shape, elevated to a height of $50 \mathrm{~cm}$ and made of durable, high-density, non-porous black plastic. The maze was placed in a darkened room, and the center of the apparatus was illuminated with a $25 \mathrm{~W}$ electric bulb hanging $100 \mathrm{~cm}$ above the maze. Each rat was gently placed in the centre of the plus maze, facing one of the closed arms, immediately after a 5min adaptation period in a black plastic box $(60 \times 60 \times 35 \mathrm{~cm})$.
During a 5-min test period, the time in open arms was recorded. The ratio (\%) of time spent in the open arms to total time spent in any arm was calculated as the standard anxiety index. After each trial, the maze was wiped clean.

\section{RESULTS}

Post hoc comparisons between all the 5 groups showed a significant difference regarding the percentage of time spent in the open arms, $F(1,38)=447.550, p<0.001$.

Significant differences concerning the time spent in the open arms were also observed between the control group and the 8.125 $\mathrm{mg} / \mathrm{kg}$ of zinc hydroaspartate group $(\mathrm{p}=$ 0.044 ), between the control group and the $16.25 \mathrm{mg} / \mathrm{kg}$ of zinc hydroaspartate group ( $\mathrm{p}$ $=0.011$ ), and between control and the 32.5 $\mathrm{mg} / \mathrm{kg}$ of zinc hydroaspartate group $(\mathrm{p}=0.001)$.

No significant difference regarding the time spent open arms was found between the control group and the group which received the maximum dosage of $65 \mathrm{mg} / \mathrm{kg}$ of zinc hydroaspartate $(\mathrm{p}=0.063)$.

Furthermore, no other statistically significant differences were found between any possible pair of the experimental groups. 


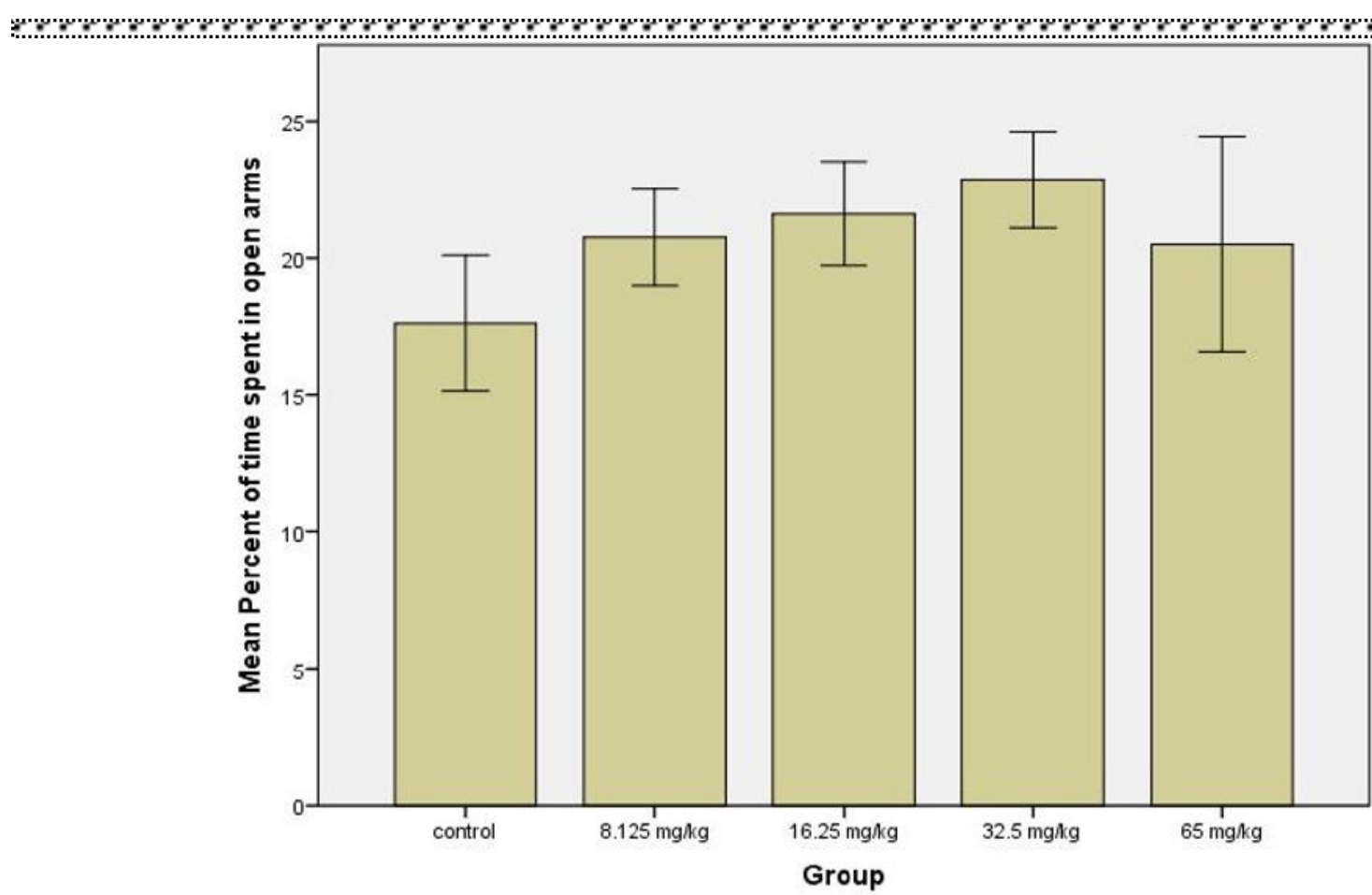

Error Bars: $95 \% \mathrm{Cl}$

Figure 1. The differences regarding the time spent in open arms (in percent) between the 5experimental groups The results are displayed as means \pm SEM for $n=8$ rats for each experimental group.

\section{Discussion}

When we first started the study, the main goal of our research team was to discover if a zinc treatment for two weeks will influence the anxiety-like behaviour of rats in the elevated plus maze. Furthermore, we assumed that a decrease in the anxiety-like behaviour of the rats would be proportional with an increase in the dosage of zinc treatment. In addition, we also wanted to ascertain if an upper threshold exist, for the hypothesised improvement in the rats' anxiety related behaviour. In other words, we searched for the optimal zinc hydroaspartate dosage, equivalent to the maximum improvement in the time spent in the open arms.

The results from the statistical analysis showed that 3 out of the 4 dosages were efficient in reducing the anxiety-like behaviours in rats. More specifically, post hoc analysis showed that the rats from the control group spent significantly less time in the open arms of the elevated plus maze compared to the rats which received the lower doses of zinc of $8.125 \mathrm{mg} / \mathrm{kg}$ ( $\mathrm{p}=0.044), 16.25 \mathrm{mg} / \mathrm{kg}$ $(\mathrm{p}=0.011)$ and $32.5 \mathrm{mg} / \mathrm{kg}$ of $(\mathrm{p}=0.001)$.

However, the maximum dosage of zinc hydroaspartate $(65 \mathrm{mg} / \mathrm{kg})$ did not improve significantly the time in the open arms in the treated rats when compared to the control group ( $\mathrm{p}=0.063)$. These results suggest that a dose of $8.125 \mathrm{mg} / \mathrm{kg}$ of zinc hydroaspartate is sufficient for inducing significant improvements in anxiety-like behaviour of rats.

Increasing dosage of the zinc does not seem to significantly reduce the anxiety levels in rats. Furthermore, a high dose of $65 \mathrm{mg} / \mathrm{kg}$ of zinc seem to have no significant effect on the anxiety related behaviour of the rats.

In addition, the assertion that a low dose of zinc is sufficient for optimal results in reducing anxiety levels in rats is also supported by our results that showed no 
s

significant differences between the groups that received the lower dose of $8.125 \mathrm{mg} / \mathrm{kg}$ of zinc the groups receiving higher doses of $16.25 \mathrm{mg} / \mathrm{kg}$ and $32.5 \mathrm{~g} \mathrm{mg} / \mathrm{kg}$ and the group that received the highest dose of $\mathrm{mg} / \mathrm{kg}$ of zinc.

The results of our study are similar to those reported by previous studies on the possible correlation between anxiety and zinc supplementing in animal models, which demonstrated that zinc is involved in the pathophysiology of anxiety (31-33).

Also, the zinc supplementation has been demonstrated in preclinical studies to decrease anxiety-like behaviour.

Furthermore, two recent studies showed that a rodents fed a zinc deficient diet for a prolonged period of time exhibited a significantly higher rate of anxiety-like behaviours $(34,35)$.

Whereas the correlation between an optimal zinc level and a low level of anxiety has been described, the mechanism responsible for the anxiolytic action of zinc is still unknown. Different authors have suggested various theories to support this correlation. Thus, J. Kotlinska (36) states that the beneficial action of zinc on anxiety may be related to the modulation of glutamate and GABA systems (36).

Examining the zinc antidepressant-like activity, other authors have speculated that the anxiolytic effect of zinc may be related to its antagonism to NMDA and mGluR5 glutamate receptors $(37,38)$.

A third theory suggests serotonergic receptors to play an essential role in the anxiolytic effect of zinc (39). Clearly, future studies are needed to elucidate the exact mechanisms that underlie this apparent anxiolytic effect of zinc, while these data could also exert an important scientific and possible therapeutically relevance.

\section{CONCLUSIONS}

These initial results described in the present study suggest a promising relevance for zinc in anxiety-related and also advocate for further theoretical research in this area considering oxidative stress related mechanisms.

\section{ACKNOWLEDGMENTS}

The authors state that there are no declared conflicts of interest regarding this paper.

\section{REFERENCES}

1. C. Brown, R. Dyck, Distribution of zincergic neurons in the mouse forebrain. J Comp Neurol. 479, 156-167 (2004).

2. C. Frederickson, S. Suh, D. Silva, C. Frederickson, R. Thompson. Importance of zinc in the central nervous system: the zinc-containing neuron. J Nutr. 130, 1471-1483 (2000).

3. H. Sandstead, C. Frederickson, J. Penland. History of zinc as related to brain function. J Nutr. 130, 496-502 (2000).

4. A. Takeda, Movement of zinc and its functional significance in the brain. Brain Res Rev. 34, 137-48 (2000).

5. A. Takeda, Zinc homeostasis and functions of zinc in the brain. BioMetals.14, 343-52 (2001). 
r.\%\%

6. M. Golub, C. Keen, M. Gershwin, A. Hendrickx, Developmental zinc deficiency and behavior. J Nutr.125, 2263-71 (1995).

7. A. Takeda, S. Takefuta, S. Okada, N. Oku, Relationship between brain zinc and transient learning impairment of adult rats fed zinc-deficient diet. Brain Res. 859, 352-7 (2000).

8. K. Brown, S. Wuehler, J. Peerson, The importance of zinc in human nutrition and estimation of the blobal prevalence of zinc deficiency. Food Nutr Bull. 22, 113-25 (2001).

9. R. Gibson, Zinc: a critical nutrient in growth and development. N Z Med J. 111, 63-4 (1998).

10. M. Hambidge, Human zinc deficiency. J Nutr. 130, 1344S-9S (2000).

11. E. Halas, M. Eberhardt, M. Diers, H. Sandstead, Learning and memory impairment in adult rats due to severe zinc deficiency during lactation. Physiol Behav. 30, 371-25 81 (1983).

12. E. Halas, C. Hunt, M. Eberhardt, Learning and memory disabilities in young adult rats from mildly zinc deficient dams. Physiol Behav. 37, 451-8 (1986).

13. M. Golub, C. Keen, M. Gershwin, A. Hendrickx. Developmental zinc deficiency and behavior. J Nutr. 125, 2263-71 (1995).

14. J. Penland, H. Sandstead, N. Alcock, A preliminary report: effects of zinc and micronutrient repletion on growth and neuropsychological function of urban Chinese children. J Am Coll Nutr. 16, 268-72 (1997).

15. H. Sandstead, J. Penland, N. Alcock, Effects of repletion with zinc and other micronutrients on neuropsychologic performance and growth of Chinese children. Am J Clin Nutr. 68(2), 470S-5S (1998).

16. C. Brown, R. Dyck, Distribution of zincergic neurons in the mouse forebrain. J Comp Neurol. 479, 156-167 (2004).

17. H. Sandstead, C. Frederickson, J. Penland, History of zinc as related to brain function. J Nutr. 130, 496S-502S (2000).

18. A. Takeda, Movement of zinc and its functional significance in the brain. Brain Res Rev. 34, 137-148 (2000).

19. A. Cichy, M. Sowa-Kuæma, B. Legutko, L. Pomierny- Chamio, Zinc-induced adaptive changes in NMDA/glutamatergic and serotonergic receptors. Pharmacol Rep. 61, 1184-1191 (2009).

20. M. Maes, P. D’haese, S. Scharpe, Hypozincemia in depression. J Affect Disord. 31,135-140 (1994).

21. I. Mcloughlin, S. Hodge, Zinc in depressive disorder. Acta Psychiatr Scand. 82, 451-453 (1990).

22. W. Opoka, M. Sowa-Kuæma, K. Stachowicz, Early lifetime zinc supplementation protects zincdeficient dietinduced alterations. Pharmacol Rep. 62, 1211-1217 (2010).

23. G. Nowak, B. Szewczyk, J. Wieroñska, Antidepressant-like effects of acute and chronic treatment with zinc in forced swim test and olfactory bulbectomy model in rats. Brain Res Bull. 61, 159-164 (2003).

24. B. Kroczka, P. Brañski, A. Paucha, A. Pilc, G. Nowak, Antidepressant-like properties of zinc in rodent forced swim test. Brain Res Bull. 55, 297-300 (2001).

25. K. Cieoelik, B. Klenk-Majewska, Z. Danilczuk, A. Wróbel, Influence of zinc supplementation on imipramine effect in chronic unpredictable stress (CUS) model in rats. Pharmacol Rep. 59, 4652 (2007).

26. G. Nowak, M. Siwek, D. Dudek, A. Ziêba, A. Pilc, Effect of zinc supplementation on antidepressant therapy in unipolar depression: a preliminary placebo-controlled study. Pol J Pharmacol. 55, 1143-1147 (2003). 
27. M. Siwek, D. Dudek, I. Paul, M. Sowa-Kuæma, A. Zieba, P. Popik, Zinc supplementation augments efficacy of imipramine in treatment resistant patients: A double blind, placebo-controlled study. J Affect Disord. 118, 187-95 (2009).

28. B. Kroczka, P. Brañski, A. Paucha, A. Pilc, G. Nowak, Antidepressant-like properties of zinc in rodent forced swim test. Brain Res Bull. 55, 297-300 (2001).

29. G. Nowak, M. Siwek, D. Dudek, A. Ziêba, A. Pilc, Effect of zinc supplementation on antidepressant therapy in unipolar depression: a preliminary placebo-controlled study. Pol J Pharmacol. 55, 1143-1147 (2003).

30. S. Pellow, S. File, Anxiolytic and anxiogenic drug effects on exploratory activity in an elevated plus-maze: a novel test of anxiety in the rat. Pharmacol Biochem Behav. 24, 525-529 (1986).

31. B. Szewczyk, M. Kubera, G. Nowak. The role of zinc in neurodegenerative inflammatory pathways in depression. Progr Neuro-Psychopharmacol Biol Psychiatry. 35, 693-701 (2011).

32. B. Szewczyk, E. Poleszak, A. Pilc, G. Nowak, Ionic glutamate modulators in depression (Zinc, Magnesium), Springer Basel AG, 21-38 (2010).

33. B. Szewczyk, E. Poleszak, M. Sowa-Kuæma, Antidepressant activity of zinc and magnesium in view of current hypotheses of antidepressant action. Pharmacol Rep. 60, 588-599 (2008).

34. A. Takeda, H. Tamano, F. Kan, H. Itoh, N. Oku, Anxietylike behavior of young rats after 2week zinc deprivation. Behav Brain Res. 177, 1-6 (2007).

35. N. Whittle, G. Lubec, N. Singewald, Zinc deficiency induces enhanced depression-like behavior and altered limbic activation reversed by antidepressant treatment in mice. AminoAcids. 36, 147158 (2009).

36. J. Kotlinska, S. Liljequist, A characterization of anxiolytic- like actions induced by the novel NMDA/glycine site antagonist. Psychopharmacology. 135, 175-181 (1994).

37. A. Plaznik, W. Palejko, M. Nazar M, Effects of antagonists at the NMDAreceptor complex in two models of anxiety. Eur Neuropsychopharmacol. 4, 503-512 (1994).

38. P. Paoletti, A. Vergnano, B. Barbour, M. Casado, Zinc at glutamatergic synapses. Neuroscience. 158, 126-136 (2009).

39. B. Szewczyk, E. Poleszak, P. Wlaÿ, A. Wróbel, E. Blicharska, A. Cichy, M. Dyba, The involvement of serotonergic system in the antidepressant effect of zinc in the forced swim test. Prog Neuropsychopharmacol Biol Psychiatry. 33, 323-329 (2009).

\section{Correspondence: \\ Constantin Truş,}

Associate Professor, Department of Morphological and Functional Sciences, Faculty of Medicine, Dunarea de Jos University, Galaţi, Romania, dilconstantin@yahoo.com 